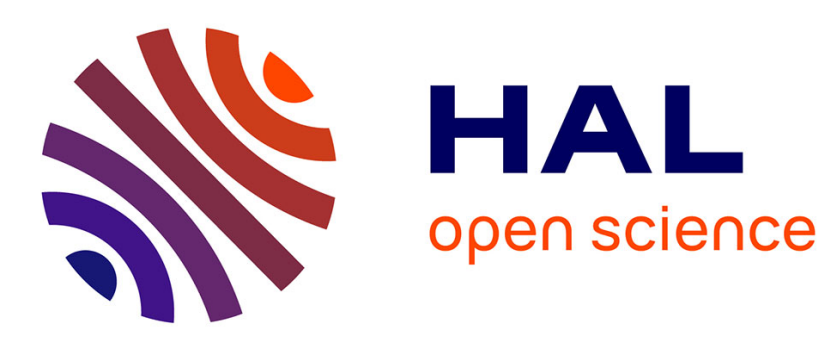

\title{
Stress relaxation coefficient and formulation for soft soils
} Zhen-Yu Yin, Q. Zhu, J. Yin, Q. Ni

\section{To cite this version:}

Zhen-Yu Yin, Q. Zhu, J. Yin, Q. Ni. Stress relaxation coefficient and formulation for soft soils.

Géotechnique Letters, 2014, 4 (1), pp.45-51. 10.1680/geolett.13.00070 . hal-01007329

\section{HAL Id: hal-01007329 \\ https://hal.science/hal-01007329}

Submitted on 22 Feb 2018

HAL is a multi-disciplinary open access archive for the deposit and dissemination of scientific research documents, whether they are published or not. The documents may come from teaching and research institutions in France or abroad, or from public or private research centers.
L'archive ouverte pluridisciplinaire HAL, est destinée au dépôt et à la diffusion de documents scientifiques de niveau recherche, publiés ou non, émanant des établissements d'enseignement et de recherche français ou étrangers, des laboratoires publics ou privés. 


\title{
Stress relaxation coefficient and formulation for soft soils
}

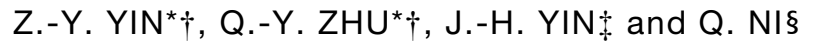

\begin{abstract}
Current studies rarely investigate the stress relaxation behaviour of soft soils. This paper proposes a practically useful coefficient with a formulation based on the behaviour of stress relaxation under onedimensional conditions. Firstly, the stress relaxation coefficient is proposed after summarising stress relaxation test results according to the linear relationship between the vertical stress and time in a double logarithmic plot. Secondly, from the newly developed rate-dependency based elastoviscoplastic formulations, an analytical solution for stress relaxation is derived. A unique relationship connecting the stress relaxation coefficient, the secondary compression coefficient and the ratedependency coefficient is then obtained. The applicability of the stress relaxation formulation with its key coefficient to determine time-dependent parameters is finally validated with published experimental results on reconstituted illite and Berthierville clay.
\end{abstract}

KEYWORDS: clays; laboratory tests; time dependence

\section{NOTATION}

$C_{\mathrm{c}}$

$C_{\mathrm{s}}$

$C_{\alpha \mathrm{e}}$

CI

$e$

$e_{0}$

$q$

$q_{0}$

$q(\varepsilon, t)$

$t_{0}$

$t_{\text {ie }}$

$R_{\alpha}$
$w$

$w_{\mathrm{L}}$

$w_{\mathrm{P}}$

$\beta$

$\varepsilon_{\mathrm{v}}^{\mathrm{vp}}$

$\dot{\varepsilon}_{\mathrm{V}}^{\mathrm{V}}$
$\dot{\varepsilon}_{\mathrm{V}}^{\mathrm{e}}$

$\sigma_{\mathrm{V}}^{\prime}$

$\sigma_{\text {vi }}^{\prime}$ experimental constant relating to stress relaxation slope of the normal compression line in $e-\log \left(\sigma_{\mathrm{v}}^{\prime}\right)$ plane slope of the swelling line in $e-\log \left(\sigma_{\mathrm{v}}^{\prime}\right)$ plane secondary compression coefficient (based on $e-\log (t)$ curve)

clay content

void ratio

initial void ratio

deviatoric stress

deviatoric stress at time $t_{0}$

deviatoric stress acting at a given axial strain $\varepsilon$ at time $t$

time at the beginning of stress relaxation

equivalent time

stress relaxation coefficient

water content

liquid limit

plastic limit

rate-dependency coefficient

viscoplastic volumetric strain

volumetric strain rate

elastic volumetric strain rate

reference volumetric strain rate

viscoplastic volumetric strain rate

initial preconsolidation pressure corresponding to $\dot{\varepsilon}_{V}$

effective vertical stress

initial effective vertical stress at the starting of stress relaxation
*Lunan University, Ecole Centrale de Nantes, UMR CNRS GeM, Nantes, France

$\dagger$ Department of Civil Engineering, Shanghai Jiao Tong University, Shanghai, China

Department of Civil and Environmental Engineering, The Hong Kong Polytechnic University, Hong Kong

$\S$ Department of Civil Engineering, University of Warwick, Coventry, UK

\section{INTRODUCTION}

Natural soft clays exhibit significant time-dependency under laboratory and in situ conditions due to their viscosity. Typically, tests at different loading rates (e.g. Graham et al., 1983; Leroueil et al., 1985; Sheahan et al., 1996; Kim \& Leroueil, 2001; Karstunen \& Yin, 2010; Yin \& Karstunen, 2011; Yin et al., 2010b, 2011) or creep tests (e.g. Yin \& Graham, 1989; Kutter \& Sathialingam, 1992; Sheahan, 1995; Vermeer \& Neher, 1999; Yin et al., 2010a; Wang \& Yin, 2013, Yin et al., 2013) are conducted to evaluate the timedependent properties of soils. A few stress relaxation tests (e.g. Lacerda \& Houston, 1973; Yin \& Graham, 1989; Sheahan et al., 1994; Fodil et al., 1997; Kim \& Leroueil, 2001; Yin \& Hicher, 2008) have also been carried out and used to investigate the stress relaxation behaviour under different conditions. However, due to a lack of studies concerning the relationship between the key parameters of stress relaxation and strain-rate-dependency or creep parameters, the stress relaxation test is still not widely used to determine the timedependency related parameters of soft soils.

This paper attempts to propose a stress relaxation coefficient with a formulation describing stress relaxation versus time, and investigates its relevance with the strainrate-dependency parameter and the secondary compression coefficient. First, studies on stress relaxation are briefly summarised and discussed. A new stress relaxation coefficient based on the stress relaxation oedometer test - one of the simplest tests for soils - is then proposed. By deriving a newly developed rate-dependency based formulation, a stress relaxation formulation is proposed and relationships connecting the stress relaxation coefficient, the secondary compression coefficient and the rate-dependency coefficient are obtained. Published experimental results on reconstituted illite and Berthierville clay are used to validate the proposed formulation and coefficient, and the relationships between different time-dependency parameters.

\section{EXPERIMENTAL EVIDENCE AND CURRENT APPROACHES FOR STRESS RELAXATION} Experimental investigations

Stress relaxation tests on different soft clays under different conditions have been carried out. These include tests on 
- undisturbed soft San Francisco Bay Mud $\left(w_{\mathrm{L}}=88 \%\right.$, $\left.w_{\mathrm{P}}=36 \%\right)$ under triaxial undrained conditions by Lacerda \& Houston (1973) (Fig. 1(a))

- reconstituted Hong Kong marine deposit $\left(w_{\mathrm{L}}=60 \%\right.$, $w_{\mathrm{P}}=28 \%$ ) under triaxial undrained conditions by Zhu et al. (1999) (Fig. 1(b))

- natural Le Flumet clay $\left(w_{\mathrm{L}}=38 \%, w_{\mathrm{P}}=24 \%\right)$ under triaxial drained conditions by Fodil et al. (1997) (Fig. 1(c))

- natural Saint-Herblain clay $\left(w_{\mathrm{L}}=96 \%, w_{\mathrm{P}}=54 \%\right)$ under pressuremeter conditions by Yin \& Hicher (2008) (Fig. 1(d))

- reconstituted illite $\left(w_{\mathrm{L}}=61 \%, w_{\mathrm{P}}=26 \%\right)$ under onedimensional (1D) conditions by Yin \& Graham (1989) (Fig. 1(e))

- Berthierville clay $\left(w_{\mathrm{L}}=43 \%, w_{\mathrm{P}}=22 \%\right)$ by Kim \& Leroueil (2001) (Fig. 1(f))

- reconstituted Boston blue clay $\left(w_{\mathrm{L}}=42 \%, w_{\mathrm{P}}=23 \%\right)$ by Sheahan et al. (1994) under triaxial undrained conditions (Fig. 1(g)).

Based on these results, different expressions for the relationship between stresses and time were assumed, as follows.

\section{Current approaches and limitations}

Based on stress relaxation tests on various materials under triaxial stress conditions, Lacerda \& Houston (1973) proposed a formulation of stress relaxation expressed as

$$
\frac{q}{q_{0}}=1-s \log \left(\frac{t}{t_{0}}\right) \text { for } t>t_{0}
$$

where $s$ represents the slope of the relaxation curve in a $q-$ $\log (t)$ diagram and relates to the deviatoric stress level. It is noted that one of the problems with equation (1) is that it predicts a negative stress because of the semi-logarithmic function with a large value of time $t$.

Later, Prevost (1976) developed a phenomenological approach to describe the stress relaxation behaviour of soils, expressed as

$$
\begin{aligned}
& q\left(\varepsilon_{1 \cdot 0}, t\right)=q\left(\varepsilon_{1 \cdot 0}, t\right)- \\
& {\left[q\left(\varepsilon_{1 \cdot 0}, t\right)-q\left(\varepsilon_{1 \cdot 0}, 0\right)\right] \tanh \left[b \ln \left(\frac{t}{t_{0}}\right)\right] \text { for } t>t_{0}}
\end{aligned}
$$

Equation (2) is capable of describing non-linear stress relaxation in $q-\log (t)$ space and operates with a final relaxed state of deviator stress when the time tends toward infinity. However, this approach needs six input parameters, which is inconvenient.

Yin \& Graham (1989) proposed a formulation for the stress decay with time in stress relaxation under 1D conditions as

$$
\sigma_{\mathrm{v}}^{\prime}=\sigma_{\mathrm{vi}}^{\prime}\left(\frac{t_{\mathrm{ie}}+t_{0}}{\left(C_{\mathrm{c}} / C_{\mathrm{s}}\right) t+t_{\mathrm{ie}}+t_{0}}\right)^{C_{\text {ee }} / C_{\mathrm{c}}}
$$

with

$$
t_{\mathrm{ie}}=-t_{0}+t_{0} \exp \left(\left(\varepsilon_{\mathrm{v}}-\varepsilon_{\mathrm{v} 0}^{\mathrm{ep}}\right) \frac{1+e_{0}}{C_{\alpha \mathrm{e}}} \ln 10\right)\left(\frac{\sigma_{\mathrm{v}}^{\prime}}{\sigma_{\mathrm{v} 0}^{\prime}}\right)^{-C_{\mathrm{c}} / C_{\alpha \mathrm{e}}}
$$

where $t_{0}$ is the reference time, $t_{\mathrm{ie}}$ is the equivalent time and $\varepsilon_{\mathrm{v} 0}^{\mathrm{ep}}$ is the strain at $\sigma_{\mathrm{v}}^{\prime}=\sigma_{\mathrm{v} 0}^{\prime}$. The formulation implies a nonlinear stress evolution with time followed by a linear stress relation with time in $\log -\log$ space, which in general agrees with experimental observations. The stress relaxation was described directly by using the secondary compression coefficient $C_{\alpha \mathrm{e}}$. However, this expression does not relate stress relaxation behaviour to either a relaxation coefficient or a constant rate-dependent parameter (Leroueil et al., 1985; Leroueil \& Marques, 1996).

While the prior works evolved towards a mathematical characterisation of relaxation behaviour, there is no unifying expression that ties together the three timedependent behaviours (i.e. stress relaxation, secondary compression and constant rate). The present work focuses on the stress relaxation coefficient and a formulation relating to behaviours of creep and rate-dependency under 1D conditions.

\section{PROPOSED STRESS RELAXATION COEFFICIENT AND FORMULATION}

Proposed stress relaxation coefficient

According to experimental results (Fig. 1), a linear relationship between the vertical stress and time in $\ln \left(\sigma_{\mathrm{v}}^{\prime}\right)-\ln (t)$ space during stress relation can be generally assumed. The slope of $\ln \left(\sigma_{\mathrm{v}}^{\prime}\right)$ versus $\ln (t)$ can then be defined as the stress relaxation coefficient $R_{\alpha}$

$$
R_{\alpha}=-\frac{\Delta \ln \left(\sigma_{\mathrm{v}}^{\prime}\right)}{\Delta \ln (t)}
$$

\section{Analytical solution of $1 D$ stress relaxation}

The authors have proposed a rate-dependency based elasto-viscoplastic model (Yin et al., 2010b, 2011, 2013) similar to those proposed by Yin \& Graham (1989), Kutter \& Sathialingam (1992) and Leoni et al. (2008) based on the creep behaviour of clay. The total strain rate under 1D conditions can be expressed as

$$
\dot{\varepsilon}_{\mathrm{v}}=\dot{\varepsilon}_{\mathrm{v}}^{\mathrm{e}}+\dot{\varepsilon}_{\mathrm{v}}^{\mathrm{vp}}=\frac{C_{\mathrm{s}}}{\left(1+e_{0}\right) \ln 10} \frac{\dot{\sigma}_{\mathrm{v}}^{\prime}}{\sigma_{\mathrm{v}}^{\prime}}+\dot{\varepsilon}_{\mathrm{v}}^{\mathrm{r}} \frac{C_{\mathrm{c}}-C_{\mathrm{s}}}{C_{\mathrm{c}}}\left(\frac{\sigma_{\mathrm{v}}^{\prime}}{\sigma_{\mathrm{p}}^{\prime \mathrm{r}}}\right)^{\beta}
$$

where $\beta$ is the rate-dependency coefficient representing the slope of the linear relationship $\log \left(\sigma_{\mathrm{p}}^{\prime}\right)-\log \left(\mathrm{d} \varepsilon_{\mathrm{v}} / \mathrm{d} t\right)$, which was first proposed by Leroueil \& Marques (1996), $\dot{\varepsilon}_{\mathrm{v}}^{\mathrm{r}}$ is the reference volumetric strain rate and the reference yield stress $\sigma_{\mathrm{p}}^{\prime \mathrm{r}}$ corresponds to $\dot{\varepsilon}_{\mathrm{v}}^{\mathrm{r}}$.

When the soil is under a stress relaxation condition, the total strain rate is zero. Thus, equation (6) can be rewritten as

$$
\begin{aligned}
& \frac{C_{\mathrm{s}}}{\left(1+e_{0}\right) \ln 10} \frac{\dot{\sigma}_{\mathrm{v}}^{\prime}}{\sigma_{\mathrm{v}}^{\prime}}=-\dot{\varepsilon}_{\mathrm{v}}^{\mathrm{r}} \frac{C_{\mathrm{c}}-C_{\mathrm{s}}}{C_{\mathrm{c}}} \\
& \left.\frac{\sigma_{\mathrm{v}}^{\prime}}{\sigma_{\mathrm{pi}}^{\mathrm{r}} \exp \left(\left\{\left[\left(1+e_{0}\right) \ln 10\right] /\left(C_{\mathrm{c}}-C_{\mathrm{s}}\right)\right\} \varepsilon_{\mathrm{v}}^{\mathrm{vp}}\right)}\right)^{\beta}
\end{aligned}
$$

where $\sigma_{\mathrm{pi}}^{\prime \mathrm{r}}$ is the initial value of the current reference stress corresponding to the start of stress relaxation. During stress relaxation, the viscoplastic strain is equal to the negative value of elastic strain

$$
\varepsilon_{\mathrm{v}}^{\mathrm{vp}}=-\int \frac{C_{\mathrm{s}}}{\left(1+e_{0}\right) \ln 10} \frac{\dot{\sigma}_{\mathrm{v}}^{\prime}}{\sigma_{\mathrm{v}}^{\prime}} \mathrm{d} t
$$

Since

$$
\int \frac{{\dot{\sigma}}_{\mathrm{v}}^{\prime}}{\sigma_{\mathrm{v}}^{\prime}} \mathrm{d} t=\ln \left(\sigma_{\mathrm{v}}^{\prime}\right)-\ln \left(\sigma_{\mathrm{vi}}^{\prime}\right)
$$

$\left(\sigma^{\prime}{ }_{\text {vi }}\right.$ is the initial vertical stress at the starting of stress relaxation), substituting equation (8), equation (7) can be further transformed to 


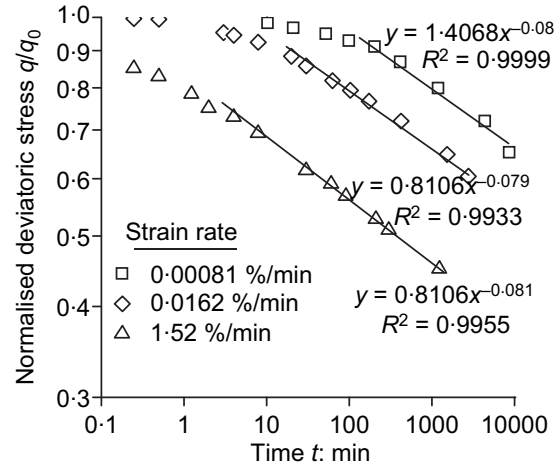

(a)

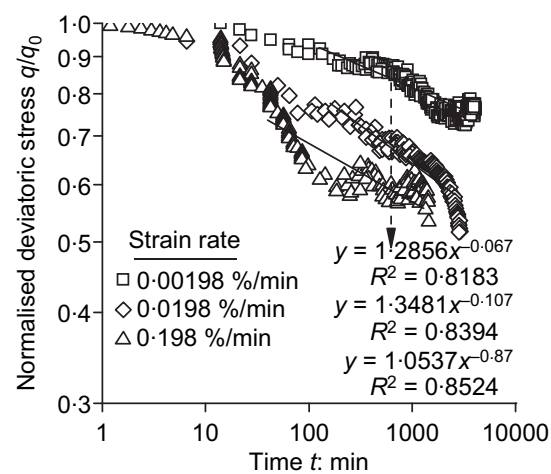

(c)

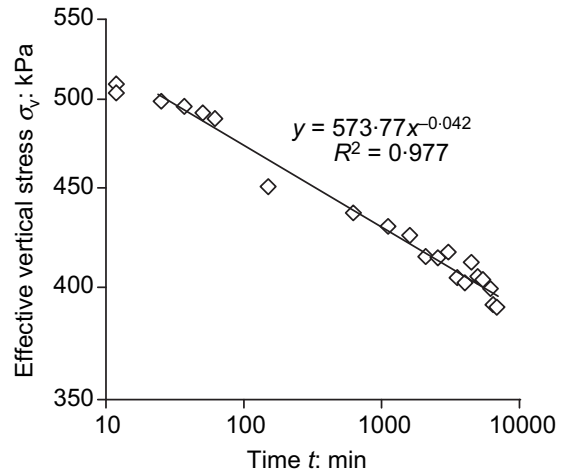

(e)

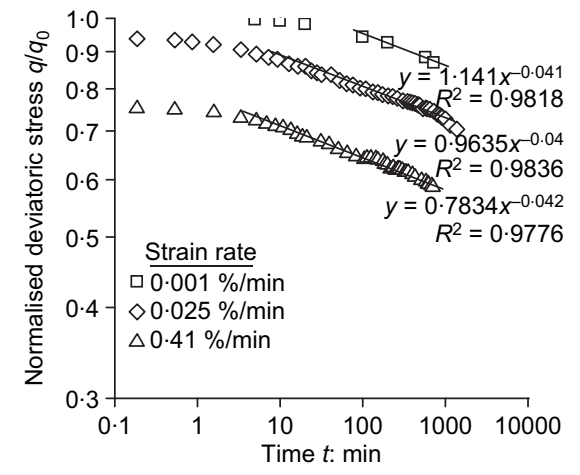

(b)

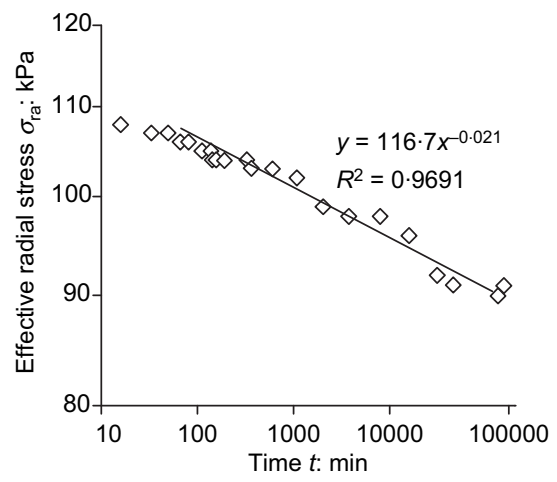

(d)

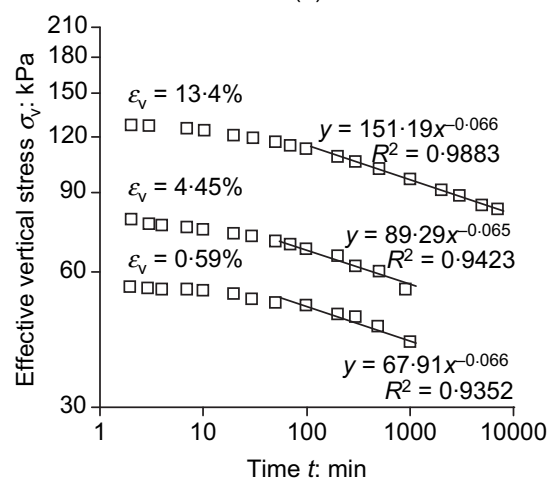

(f)

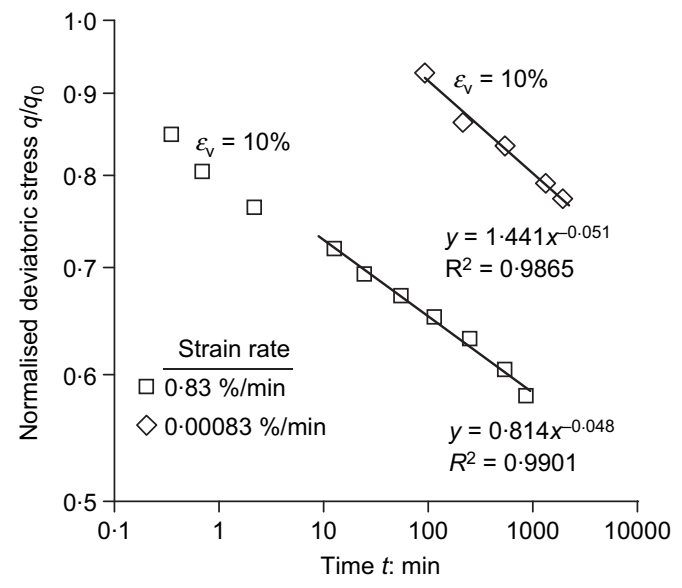

(g)

Fig. 1. Results of stress relaxation tests on different clays under different conditions: (a) undisturbed soft San Francisco Bay mud, triaxial undrained conditions; (b) reconstituted Hong Kong marine deposit, triaxial undrained conditions; (c) natural Le Flumet clay, triaxial drained conditions; (d) natural Saint-Herblain clay, pressuremeter conditions; (e) reconstituted illite, 1D conditions, strain rate $3.7 \times 10^{-6} / \mathrm{s}$; (f) Berthierville clay, 1D conditions, strain rate $6.35 \times 10^{-6} / \mathrm{s}$; (g) reconstituted Boston blue clay, triaxial undrained conditions 


$$
\begin{aligned}
& \frac{C_{\mathrm{s}}}{\left(1+e_{0}\right) \ln 10} \frac{\dot{\sigma}_{\mathrm{v}}^{\prime}}{\sigma_{\mathrm{v}}^{\prime}}= \\
& \left.-\dot{\varepsilon}_{\mathrm{v}}^{\mathrm{r}} \frac{C_{\mathrm{c}}-C_{\mathrm{s}}}{C_{\mathrm{c}}} \frac{\sigma_{\mathrm{v}}^{\prime}}{\sigma_{\mathrm{pi}}^{\prime \mathrm{r}}\left(\dot{\sigma}_{\mathrm{v}}^{\prime} / \dot{\sigma}_{\mathrm{vi}}^{\prime}\right)^{-C_{\mathrm{s}} /\left(C_{\mathrm{c}}-C_{\mathrm{s}}\right)}}\right)^{\beta}
\end{aligned}
$$

In general form, the equation can be written as

$$
\dot{\sigma}_{\mathrm{v}}^{\prime}=A\left(\sigma_{\mathrm{v}}^{\prime}\right)^{m}
$$

with

$$
\left.A=-\dot{\varepsilon}_{\mathrm{v}}^{\mathrm{r}} \frac{\ln 10\left(1+e_{0}\right)\left(C_{\mathrm{c}}-C_{\mathrm{s}}\right)}{C_{\mathrm{c}} C_{\mathrm{s}}} \frac{1}{\sigma_{\mathrm{pi}}^{\mathrm{r}} \cdot \sigma_{{ }_{\mathrm{vi}}}^{\prime} C_{\mathrm{s}} /\left(C_{\mathrm{c}}-C_{\mathrm{s}}\right)}\right)^{\beta}
$$

and

$$
m=\frac{C_{\mathrm{c}} \beta}{C_{\mathrm{c}}-C_{\mathrm{s}}}+1
$$

where $A$ and $m$ are both constant values during stress relaxation. Solving this first-order differential equation with the initial condition $\sigma_{\mathrm{vi}}^{\prime}$ for $t=0$, the analytical solution for stress relaxation is

$$
\sigma_{\mathrm{v}}^{\prime}=\left[A(1-m) t+{\sigma_{\mathrm{vi}}^{\prime 1-m}}^{1 /(1-m)}\right.
$$

Substituting the constants $A$ and $m$ into equation (12), the evolution of vertical stress is expressed as

$$
\begin{aligned}
& \sigma_{\mathrm{v}}^{\prime}=\left(-\dot{\varepsilon}_{\mathrm{v}}^{\mathrm{r}} \frac{\ln 10\left(1+e_{0}\right)\left(C_{\mathrm{c}}-C_{\mathrm{s}}\right)}{C_{\mathrm{c}} C_{\mathrm{s}}}\right. \\
& \left.\frac{1}{\sigma_{\mathrm{pi}}^{\prime} \cdot \sigma_{\mathrm{vi}}^{\prime \mathrm{C}_{\mathrm{s}} /\left(C_{\mathrm{c}}-C_{\mathrm{s}}\right.}}\right)^{\beta}\left(-\frac{C_{\mathrm{c}} \beta}{C_{\mathrm{c}}-C_{\mathrm{s}}}\right) t \\
& \left.+\sigma_{\mathrm{vi}}^{\prime-\frac{C_{\mathrm{c}} \beta}{\mathrm{C}_{\mathrm{c}}-C_{\mathrm{s}}}}\right)^{-\frac{C_{\mathrm{c}}-C_{\mathrm{s}}}{C_{\mathrm{c}} \beta}}
\end{aligned}
$$

\section{Deriving stress relaxation coefficient with other time-dependency parameters}

Based on the analytical solution of stress relaxation (equation (12)), $R_{\alpha}$ can be derived as follows. In the stage of stress relaxation, after a certain time, $\sigma_{\mathrm{vi}}^{\prime 1-m}$ become insignificant compared to $A(1-m) t$. Hence, the differential of $\ln \left(\sigma_{\mathrm{v}}^{\prime}\right) / \ln (t)$ is expressed as

$$
\frac{\partial \ln \left(\sigma_{\mathrm{v}}^{\prime}\right)}{\partial \ln (t)}=\frac{1}{1-m}=-\frac{C_{\mathrm{c}}-C_{\mathrm{s}}}{C_{\mathrm{c}} \beta}
$$

Comparing equation (5) with equation (14), the stress relaxation coefficient $R_{\alpha}$ can be expressed in terms of compression parameters $C_{\mathrm{c}}, C_{\mathrm{s}}$ and the rate-dependency coefficient $\beta$

$$
R_{\alpha}=\frac{C_{\mathrm{c}}-C_{\mathrm{s}}}{C_{\mathrm{c}} \beta} \text { or } \beta=\frac{C_{\mathrm{c}}-C_{\mathrm{s}}}{C_{\mathrm{c}} R_{\alpha}}
$$

For natural soft clays, $C_{\mathrm{c}} / C_{\mathrm{s}}$ varies generally from 5 to 15 . According to this relationship, $\beta$ can be expressed by $R_{\alpha}$ directly as described by equation (15). Figure 2 shows that the relationship between $\beta$ and $R_{\alpha}$ is confined to a narrow range for a reasonable range of $C_{\mathrm{c}} / C_{\mathrm{s}}$.

Furthermore, Kutter \& Sathialingam (1992) presented the quantity $\left(C_{\mathrm{c}}-C_{\mathrm{s}}\right) / C_{\alpha \mathrm{e}}$ and Yin et al. $(2010 \mathrm{~b}, 2011)$ related it to the rate-dependency coefficient $\beta$ (Leoni et al., 2008) as

$$
\beta=\frac{C_{\mathrm{c}}-C_{\mathrm{s}}}{C_{\alpha \mathrm{e}}} \text { or } C_{\alpha \mathrm{e}}=\frac{C_{\mathrm{c}}-C_{\mathrm{s}}}{\beta}
$$

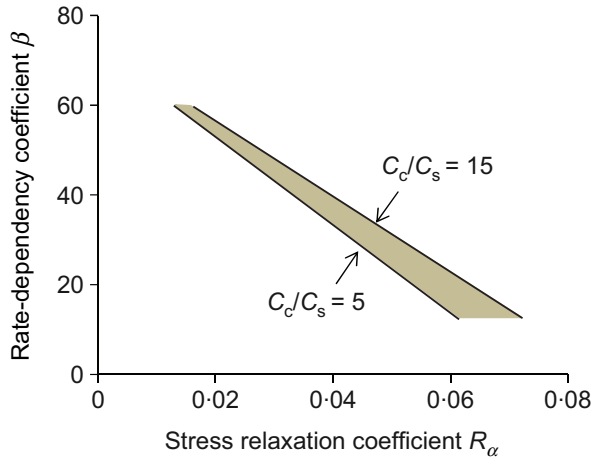

Fig. 2. Relationship between $\beta$ and $R_{\alpha}$ for a reasonable range of ratio $C_{\mathrm{c}} / C_{\mathrm{s}}$ for soft clays

Hence, substituting $\beta$ from equation (16) into equation (15), $R_{\alpha}$ can also be expressed by $C_{\alpha \mathrm{e}}$ or the inverse

$$
R_{\alpha}=\frac{C_{\alpha \mathrm{e}}}{C_{\mathrm{c}}} \text { or } C_{\alpha \mathrm{e}}=R_{\alpha} C_{\mathrm{c}}
$$

Mesri \& Castro (1987) showed that $C_{\alpha \mathrm{e}}$ is related to $C_{\mathrm{c}}$ of the soil and, more precisely, that the ratio $C_{a \mathrm{e}} / C_{\mathrm{c}}$ is constant for a given soil. Moreover, they summarised a range of values for a number of clays published in the literature and found that $C_{\alpha \mathrm{e}} / C_{\mathrm{c}}$ is $0.04 \pm 0.01$ for most inorganic soft clays and $0 \cdot 05 \pm 0 \cdot 01$ for highly organic plastic clays. Based on equation (17), it is interesting to note that this classification is also related to the stress relaxation coefficient. Consequently, previous studies on the properties of $C_{\alpha \mathrm{e}} / C_{\mathrm{c}}$ can be used for $R_{\alpha}$.

According to Mesri \& Castro (1987), $C_{\mathrm{c}}$ can be different for different loading increments. For soils with a constant $C_{\mathrm{c}}$, many investigators have studied the relationship between $C_{\mathrm{c}}$ and clay physical properties and proposed correlation equations. The generally accepted correlation is the one proposed by Terzaghi \& Peck (1967) as $C_{\mathrm{c}}=$ $0.009\left(w_{\mathrm{L}}-10\right)$. According to this, the ratio of $C_{\alpha \mathrm{e}} / R_{\alpha}$ varies significantly with the liquid limit of soils.

Overall, based on the derived expressions between $R_{\alpha}, \beta$ and $C_{\alpha e}$, a unique relationship among the three timedependency related parameters was obtained, which suggests that once $R_{\alpha}$ is measured, $\beta$ and $C_{\alpha \mathrm{e}}$ can be subsequently obtained. Therefore, the relaxation test can be used to determine the time-dependency related parameters. Note that the stress relaxation test can be a test stage during a constant rate of strain (CRS) test: a CRS test up to $\varepsilon_{\mathrm{v}}=20 \%$ at $\mathrm{d} \varepsilon_{\mathrm{v}} / \mathrm{d} t=10^{-6} / \mathrm{s}$ (the order used by Yin \& Graham (1989) and Kim \& Leroueil (2001)) followed by a 1 day stress relaxation stage needs a total of $3 \cdot 3$ days, which is more beneficial than conventional oedometer testing in terms of time cost.

\section{EXPERIMENTAL VALIDATION}

In order to evaluate the applicability of the proposed stress relaxation formulation and its coefficient in studies of the time-dependent behaviour of soft clay, experimental validations were performed using test results on reconstituted illite by Yin \& Graham (1989) and on Berthierville clay by Kim \& Leroueil (2001).

\section{Experimental description}

Yin \& Graham (1989) conducted a stress relaxation test following stepped CRS tests on reconstituted illite. The physical properties of the clay are summarised in Table 1. 
Table 1. Physical properties of selected clays

\begin{tabular}{l|c|c|c|c|c}
\hline & $e_{0}$ & $w: \%$ & $w_{\mathrm{P}}: \%$ & $w_{\mathrm{L}}: \%$ & CI: \% \\
\hline Reconstituted illite & $-\overline{73}$ & 51 & 26 & 61 & 61 \\
Berthierville clay & $1 \cdot 73$ & 22 & 43 & 81 \\
\hline
\end{tabular}

The stepped-loading portion of the test produced $C_{\mathrm{c}} /(1+$ $\left.e_{0}\right)=0.23, C_{\mathrm{s}} /\left(1+e_{0}\right)=0.057$ and $C_{\alpha \mathrm{e}} /\left(1+e_{0}\right)=0.009$. Moreover, $R_{\alpha}=0.042$ was obtained in the $\ln \left(\sigma_{\mathrm{v}}^{\prime}\right)-\ln (t)$ plot (Fig. 1(e)).

Kim \& Leroueil (2001) conducted a stress relaxation test with three stress relaxation stages on Berthierville clay at different strain levels during one CRS test (see Fig. 3). The physical properties of the Berthierville clay are summarised in Table 1 . The specimen was loaded by displacement control at a constant strain rate of $6.35 \times 10^{-6} / \mathrm{s}$. Three relaxation stages were conducted when the vertical strain was equal to 0.59 , 4.45 and $13.40 \%$. From Fig. $3, C_{\mathrm{c}}=1.133$ and $\mathrm{C}_{\mathrm{s}}=0.074$ were measured. Based on the three stages of stress relaxation tests (Fig. 1(f)), an average $R_{\alpha}=0.0657$ was measured.

\section{Stress relaxation behaviour}

As discussed earlier, the time-dependency related parameters $R_{\alpha}, \beta$ and $C_{\alpha \mathrm{e}}$ can each be obtained from the other two. Consequently, the analytical solution of 1D stress relaxation (equation (13)) using $\beta$ can also be expressed directly by $R_{\alpha}$. Thus, substituting equation (15) into equation (13), the stress relaxation can be expressed as follows by using $R_{\alpha}$ as a key parameter

$$
\begin{gathered}
\sigma_{\mathrm{v}}^{\prime}=\left(\dot{\varepsilon}_{\mathrm{v}}^{\mathrm{r}} \frac{\ln 10\left(1+e_{0}\right)\left(C_{\mathrm{c}}-C_{\mathrm{s}}\right)}{C_{\mathrm{c}} C_{\mathrm{s}}}\right. \\
\left.\left.\frac{1}{\sigma_{\mathrm{pi}}^{\prime r} \cdot \sigma_{\mathrm{vi}}^{\left.\prime C_{\mathrm{i}} / / C_{\mathrm{c}}-C_{\mathrm{s}}\right)}}\right)^{\frac{C_{\mathrm{c}}-C_{\mathrm{s}}}{C_{\mathrm{c}} R_{\alpha}}} \frac{1}{R_{\alpha}} t+\sigma_{\mathrm{vi}}^{\prime-1 / R_{\alpha}}\right)^{-R_{\alpha}}
\end{gathered}
$$

Then, equation (18) is used to simulate the stress relaxation behaviour of both reconstituted illite and Berthierville clay. As shown in Fig. 4, the theoretical curves produced by the analytical solution can not only capture well the constant slope of stress relaxation in $\log -\log$ space, but can also adequately describe the initial evolution of stress at the beginning portion of relaxation.

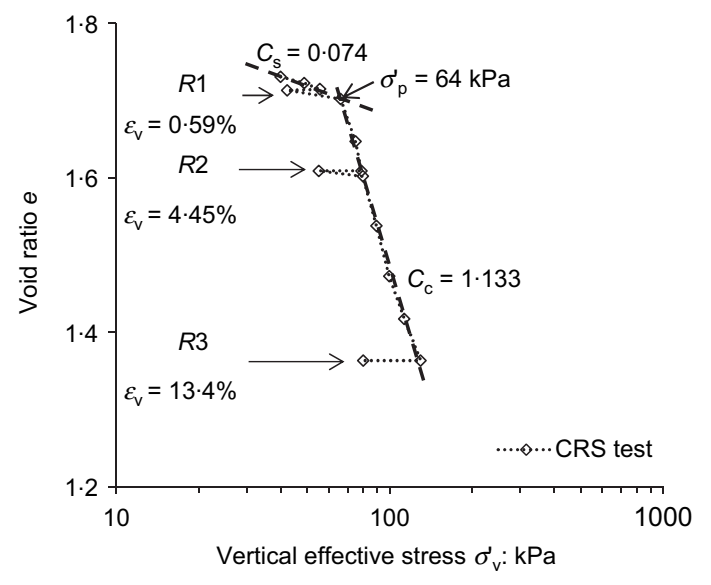

Fig. 3. Test stages of stress relaxation during a CRS test on Berthierville clay

\section{Validation for strain-rate-dependent behaviour}

As shown by equation (15), $\beta$ can also be obtained by the stress relaxation coefficient $R_{\alpha}$. In this way, $\beta=17.9$ and $\beta=14 \cdot 2$ were obtained for reconstituted illite and Berthierville clay, respectively. To identify the difference between the experimental and derived values of $\beta$, adopting the preconsolidation pressure corresponding to the constant strain rate after which the stress relaxation stage was performed, $\log \left(\sigma_{\mathrm{p} 0}^{\prime}\right)-\log \left(\mathrm{d} \varepsilon_{\mathrm{v}} / \mathrm{d} t\right)$ curves were plotted with $\beta$ derived from $R_{\alpha}$ and compared with measurements for reconstituted illite and Berthierville clay. As shown in Fig. 5, the differences between measurements and theoretical curves are rather small and the predictions agree well with the experimental results.

\section{Validation for creep behaviour}

From 1D oedometer creep tests, $C_{\alpha \mathrm{e}} /\left(1+e_{0}\right)=0.009$ was measured by Yin \& Graham (1989) for reconstituted illite and an average $C_{\alpha \mathrm{e}}=0.062$ was obtained for Berthierville clay by Leroueil et al. (1988). As shown in equation (16), $C_{\alpha \mathrm{e}}$ can also be calculated by the stress relaxation coefficient $R_{\alpha}$. In this way, $C_{\alpha \mathrm{e}} /\left(1+e_{0}\right)=0.0097$ and $C_{\alpha \mathrm{e}}=0.074$ were obtained for reconstituted illite and Berthierville clay, respectively. Comparing $C_{\alpha e}$ measured from creep tests and that derived by $R_{\alpha}$, the differences are acceptable, which demonstrates the applicability of $R_{\alpha}$ in predicting $C_{\alpha \mathrm{e}}$. Note that, currently, only data for two clays are available for the validation.

Overall, all the validations showed that the stress relaxation coefficient $R_{\alpha}$ can be used to predict the other two parameters ( $\beta$ and $C_{\alpha \mathrm{e}}$ ), which reveals the unique stress-strain-strain rate law assumed by equation (6).

\section{CONCLUSIONS}

Previous studies on stress relaxation were briefly summarised and discussed. The experimental results suggest a linear relationship between vertical stress and time in the graph of $\ln \left(\sigma_{\mathrm{v}}^{\prime}\right)-\ln (t)$. Based on that, the stress relaxation coefficient $R_{\alpha}$ was proposed.

After developing the new rate-dependency based elastoviscoplastic model, the stress relaxation formulation under 1D conditions was derived. Then, a unique relationship between the stress relaxation coefficient $R_{\alpha}$, the secondary compression coefficient $C_{\alpha \mathrm{e}}$ and the rate-dependency coefficient $\beta$ was determined. This relationship indicates that $\beta$ increases with decreasing $R_{\alpha}$ and $C_{\alpha \mathrm{e}}$ increases with increasing $R_{\alpha}$. Moreover, the relationship between $\beta$ and $R_{\alpha}$ is confined in a narrow area for a reasonable range of $C_{\mathrm{c}} / C_{\mathrm{s}}$. The ratio of $C_{\alpha \mathrm{e}} / R_{\alpha}$ varies significantly with the liquid limit of soils, taking into account the correlation between $C_{\mathrm{c}}$ and the liquid limit.

Test results on reconstituted illite and Berthierville clay were adopted to evaluate the applicability of the proposed stress relaxation coefficient and formulation. The stress relaxation coefficient was measured based on stress relaxation tests for both clays. The stress relaxation formulation was used and simulated well the experimental stress relaxation behaviours of the two clays. The measured 


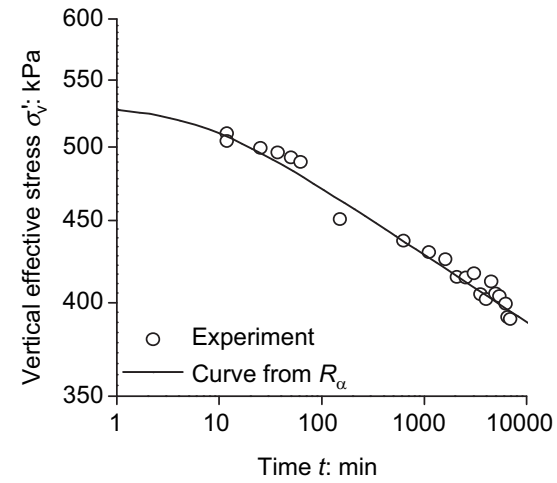

(a)

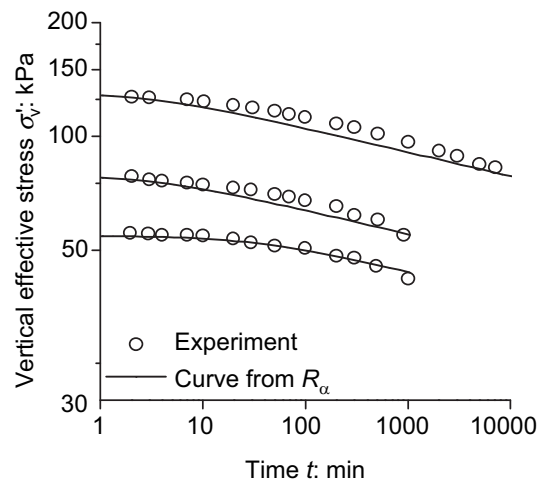

(b)

Fig. 4. Comparison of experimental and theoretical results for stress relaxation on (a) reconstituted illite and (b) Berthierville clay

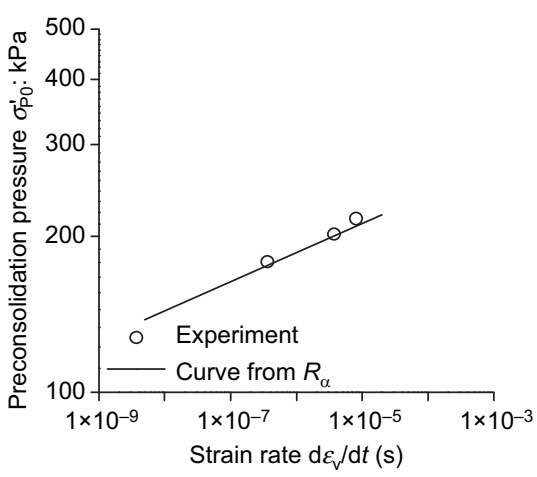

(a)

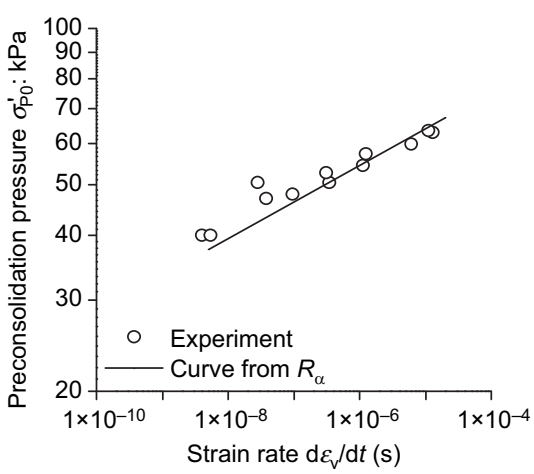

(b)

Fig. 5. Comparison of theoretical curves using $\beta$ derived from $R_{\alpha}$ and measurements on the strain-rate-dependency of preconsolidation pressure for (a) reconstituted illite and (b) Berthierville clay

$R_{\alpha}$ was then used to derive the rate-dependency parameter $\beta$ and the secondary compression coefficient $C_{\alpha e}$ to compare with experimental measurements. This demonstrated the applicability of the stress relaxation coefficient in determining other time-dependency parameters.

Further work will be carried out on stress relaxation tests for different clays under more complicated conditions (e.g. structured clays and triaxial conditions).

\section{ACKNOWLEDGEMENTS}

The authors acknowledge with gratitude financial support provided by the National Natural Science Foundation of China (grant no. 41240024, 41372285), the Research Fund for the Doctoral Program of Higher Education of China (grant no. 20110073120012) and the European project CREEP (PIAPP-GA-2011-286397).

\section{REFERENCES}

Fodil, A., Aloulou, W. \& Hicher, P. Y. (1997). Viscoplastic behaviour of soft clay. Géotechnique 47, No. 3, 581-591.

Graham, J., Crooks, J. H. A. \& Bell, A. L. (1983). Time effects on the stress-strain behaviour of natural soft clays. Géotechnique 33, No. 3, 327-340.

Karstunen, M. \& Yin, Z. Y. (2010). Modelling time-dependent behaviour of Murro test embankment. Géotechnique 60, No. $10,735-749$.

Kim, Y. T. \& Leroueil, S. (2001). Modeling the viscousplastic behavior of clays during consolidation: application to Berthierville clay in both laboratory and field conditions. Can. Geotech. J. 38, No. 3, 484- 497.
Kutter, B. L. \& Sathialingam, N. (1992). Elastic-viscousplastic modelling of the rate-dependent behaviour of clays. Géotechnique 42, No. 3, 427-441.

Lacerda, W. \& Houston, W. (1973). Stress relaxation in soils. Proc. $8^{\text {th }}$ ICSMFE 1, 221-227.

Leoni, M., Karstunen, M. \& Vermeer, P. A. (2008). Anisotropic creep model for soft soils. Géotechnique 58, No. 3, 215-226.

Leroueil, S. \& Marques, M. E. S. (1996). State of art: importance of strain rate and temperature effects in geotechnical engineering, measuring \& modelling time dependent behaviour of soils. ASCE Geotechnical Special Publication 61, 1-60.

Leroueil, S., Kabbaj, M., Tavenas, F. et al. (1985). Stress-strainstrain-rate relation for the compressibility of sensitive natural clays. Géotechnique 35, No. 2, 159-180.

Leroueil, S., Kabbaj, M. \& Tavenas, F. (1988). Study of the validity of a $\sigma^{\prime}{ }_{\mathrm{v}}-\varepsilon_{\mathrm{v}}-\mathrm{d} \varepsilon_{\mathrm{v}} / \mathrm{d} t$ model in site conditions. Soils and Found. 28, No. 3, 13-25.

Mesri, G. \& Castro, A. (1987). $C_{\alpha} / C_{\mathrm{c}}$ concept and $K_{0}$ during secondary compression. J. Geotech. Eng. ASCE 113, No. 3, 230-247.

Prevost, J. H. (1976). Undrained stress-strain-time behavior of clays. J. Geotech. Eng. ASCE 102, No. 12, 1245-1259.

Sheahan, T. C. (1995). Interpretation of undrained creep tests in terms of effective stresses. Can. Geotech. J. 32, No. 2, 373-379.

Sheahan, T. C., Ladd, C. C. \& Germaine, J. T. (1994). Timedependent triaxial relaxation behavior of a resedimented clay. Geotech. Test. J. 17, No. 4, 444452.

Sheahan, T. C., Ladd, C. C. \& Germaine, J. T. (1996). Ratedependent undrained shear behavior of saturated clay. J. Geotech. Eng. 122, No. 2, 99-108.

Terzaghi, K. \& Peck, R. B. (1967). Soil mechanics in engineering practice, 2nd ed. New York: John Wiley.

Vermeer, P. A. \& Neher, H. P. (1999). A soft soil model that accounts for creep. Proc. Plaxis Symp. Beyond 2000 in Computational Geotechnics, Amsterdam, 249-262. 
Wang, L. Z. \& Yin, Z. Y. (2013). Stress-dilatancy of natural soft clay under undrained creep condition. Int. J. Geomech. ASCE http://dx.doi.org/10.1061/(ASCE)GM.1943-5622.0000271.

Yin, J. H. \& Graham, J. (1989). Viscous elastic plastic modelling of one-dimensional time dependent behaviour of clays. Can. Geotech. J. 26, No. 2, 199-209.

Yin, J. H., Zhu, J. G. \& Graham, J. (2010a). A new elastic viscoplastic model for time-dependent behaviour of normally and overconsolidated clays: theory and verification. Can. Geotech. J. 39, No. 1, 157-173.

Yin, Z. Y. \& Hicher, P. Y. (2008). Identifying parameters controlling soil delayed behaviour from laboratory and in situ pressuremeter testing. Int. J. Num. Anal. Methods, 32, No. 12, 1515-1535.

Yin, Z. Y. \& Karstunen, M. (2011). Modelling strain-ratedependency of natural soft clays combined with anisotropy and destructuration. Acta Mech. Solida Sin. 24, No. 3, 216230

Yin, Z. Y., Chang, C. S., Karstunen, M. et al. (2010b). An anisotropic elastic viscoplastic model for soft clays. Int. J. Solids Struct. 47, No. 5, 665-677.

Yin, Z. Y., Karstunen, M., Chang, C. S. et al. (2011). Modeling time-dependent behavior of soft sensitive clay. J. Geotech. Geoenviron. Engng 137, No. 11, 1103-1113.

Yin, Z. Y., Yin, J. H. \& Huang, H. W. (2013). Rate-dependent and long-term yield stress and strength of soft Wenzhou marine clay: experiments and modeling. Mar. Georesour. Geotech. http://dx.doi.org/10.1080/1064119X.2013.797060.

Zhu, J. G., Yin, J. H. \& Luk, S. T. (1999). Time-dependent stressstrain behavior of soft Hong Kong marine deposits. Geotech. Test. J. 22, No. 2, 118-126. 